\title{
LA DIGNIDAD DE LA PERSONA HUMANA. DESDE LA FECUNDACIÓN HASTA SU MUERTE
}

\author{
Juan de Dios Vial Correa*, Ángel Rodríguez Guerro**
}

Resumen: El presente trabajo reflexiona sobre el concepto de "dignidad" desde sus orígenes y la evolución del término, en búsqueda de un sustrato filosófico y antropológico que fundamente el concepto, con el fin de que se respete la persona humana desde la fecundación hasta la muerte y la reflexión bioética tenga una base desde la cual proceder.

Palabras clave: dignidad, persona humana, bioética

\section{THE DIGNITY OF THE HUMAN BEING. FROM CONCEPTION TO DEATH}

Abstract: This work contemplates the concept of "dignity" from its origins and the evolution of the term, in search of a philosophical and anthropological substrate that grounds the concept, with the objective of the respect of the human being from its conception until death and the provision of a basis from which bioethical reflection may proceed.

Key words: dignity, human being, bioethics

\section{A DIGNIDADE DA PESSOA HUMANA. DESDE A FECUNDAÇÃO ATÉ A MORTE}

Resumo: O presente trabalho reflete sobre o conceito de "dignidade" desde suas origens e a evolução do termo. Busca um substrato filosófico e antropológico que fundamente o conceito, com a finalidade de que se respeite a pessoa humana desde a fecundação até a morte e que a reflexão bioética tenha uma base de ação.

Palabra chave: dignidade, pessoa humana, bioética

* Profesor Titular de la Facultad de Medicina, Pontificia Universidad Católica de Chile, Chile

** Profesor Adjunto de la Facultad de Medicina, Pontificia Universidad Católica de Chile, Chile Correspondencia: arodrig@med.puc.cl 


\section{Alguna nota histórica sobre el concepto $\operatorname{dignidad}(1)$}

Lo que se entiende por "dignidad" ha sufrido un cambio substancial desde que este valor surgió en la sociedad de la antigua Roma hasta que fue incorporado en la cultura cristiano-occidental: pasó de una conquista individual a ser inherente a la condición humana.

En la sociedad romana preimperial la dignidad respondía a méritos en una forma de vida, ligada por una parte a la esfera política y por otra a una recta moral. En Roma la condición principal para adquirir dignidad era la acción política, la pertenencia al Senado, junto con la integridad moral. Pertenecer a la nobleza romana, tener entre los antepasados héroes troyanos, reyes, o-como César- una diosa confería más brillos a esa dignidad. El romano defendía su dignidad, luchaba por ella, la asentaba y lucía. Ésta no tenía un orden rígido: podía aumentarse, rebajarse, perderse, restituirse. La dignidad era un logro personal que, por un lado, daba derecho a un poder $y$, por otro, por el impulso interior a ser moralmente intachable, exigía un deber.

La dignidad obligaba y lo hacía más cuanto mayor era su grado. A esa forma de vida pertenecían la magnanimidad, disciplina, austeridad, moderación y serenidad de mente. La dignidad era elitista: no todos los ciudadanos gozaban de las condiciones para llevar esa forma de vida portadora de dignidad; además, no se concebía sin libertad: era incompatible con la condición de esclavo. Según Cicerón autor, la dignidad debe apoyarse en el dominio sobre sí mismo, el abandono de toda liviandad y del actuar impulsivo.

Para el cristiano la dignidad del hombre tiene el triple fundamento en su origen divino, en su calidad de imagen y semejanza de Dios y en su finalidad en el Creador mismo. La dignidad queda así definida, para todos los hombres por igual, en relación directa con Dios, con independencia de toda otra condición: raza, nacionalidad, sexo, edad, creencias, condición social. Esa dignidad dota al hombre de ciertos derechos inalienables y de ella nacen las tareas de protección y respeto.

La evolución de este concepto a través de la historia del pensamiento occidental lleva a la conclusión de que la dignidad humana no puede ser fruto de una conquista, pues serían muchos los que, conforme al parámetro establecido, no la alcanzarían. La dignidad es intrínseca a la persona humana en razón de lo que es específico de su naturaleza: su ser espiritual. Esta dignidad es más que moral, más que ética, más que psicológica: es constitutiva del ser humano y su naturaleza es ontológica. No se la puede dar él a sí mismo ni podemos hacerla depender de su vida moral, tampoco se la puede dar el Estado -como sucedía en Roma- o la sociedad, aunque a ellos corresponda reconocerla y vigilar que no haya violaciones.

\section{La dignidad es constitutiva hasta el final de nuestros días}

En el lenguaje habitual, "dignidad" es un atributo o condición propia del ser humano. Sólo las personas tienen "dignidad". Forzando la expresión, se podría preguntar si obras de arte u obras del espíritu en general, o asociaciones humanas determinadas, no tienen también "dignidad". Es fácil ver que en cualquiera de esos casos el término "dignidad" se estaría aplicando como una derivación o extensión de la dignidad que es atributo de los seres humanos que dieron origen a la obra o a la asociación. Siempre se ve que son las personas las que tienen dignidad y no sus obras o asociaciones.

Si observamos las cualidades de hombres o cosas nos encontramos con que pueden hallarse en mayor o menor grado. Por ejemplo, las magnitudes: hay cuerpos más grandes o más pequeños, más livianos o más pesados, más veloces o más lentos. Pero también nos parece que colores, olores o sabores pueden ser más o menos intensos. En alguna forma, toda la naturaleza sensible está sujeta a medida, sus propiedades son cuantificables. En otro orden de cosas, que no son propiamente medibles, también reconocemos una suerte de magnitud: nos parece que el talento matemático, el musical, el literario, entre otros, pueden ser mayores o menores, aun cuando su estimación se parece muy poco a una simple medición. En el ámbito de las cosas morales también reconocemos gradación: hay personas más o menos valerosas o veraces. Incluso frente a un complejo conjunto de cualidades morales podemos decir que hay personas que nos parecen más respetables que otras. A primera vista, entonces, todo parece susceptible de gradación, cualquiera condición que conozcamos se puede mostrar o poseer en grados diversos.

Pero cuando hablamos de la "dignidad humana" hay un elemento central que no puede ser sometido a comparación, que no reconoce propiamente gradación. Esto es lo que expresaría la intuición de Kant de que 
hay algo que es propio, lo íntimo de cada hombre/ mujer, y que no puede ser utilizado como medio, como instrumento, sino que es siempre un fin en sí. Hay algo que provoca repulsión en el intento de poseer integralmente a un hombre como esclavo, a un nińo como objeto de placer o a un organismo humano como donador de órganos.

Todas las formas de relación humana comprenden servicios, remuneraciones, organización, limitaciones o especificaciones de la libertad de los individuos. Pero siempre -en casos de duda- percibimos un límite que no es franqueable, en el que la relación cuestionable se transforma en "usurpación", en explotación del otro. Ningún ser humano puede estar sometido a nuestro arbitrio. Hay algo en mí y en cada uno de los hombres y mujeres, que le es propio, y de lo cual nadie puede disponer. Nadie puede estar a disposición de otro como lo está el instrumento a la del operario. Esa condición del ser humano es su dignidad. Todas las cosas pueden ser transables y tienen precio; pero el hombre tiene dignidad.

Esa dignidad propia del hombre no existe en grados diversos. Sería absurdo decir que los hombres son más o menos explotables, más o menos usables, como se pueden usar las cosas en general. Esa dignidad "nuclear" o fundamental se tiene o no se tiene. No puede haber hombre que no la tenga. Ella se adquiere con la existencia y se pierde con la muerte.

Ser persona no es algo agregado, no es una cualidad o característica del ser humano: es la manera que tiene el ser humano de existir, de ser. La dignidad no está ligada a sus cualidades morales, físicas o intelectuales, sino simplemente a que este "es", al hecho de que como individuo de la especie humana tiene un lugar absolutamente especial en la creación.

La persona humana en cuanto organismo biológico está sujeta a leyes de origen, desarrollo y decadencia. Durante este trayecto es válido que ella no puede ser usada como instrumento y que es digna de acogida y de respeto. Desde el primer instante de su existencia la persona es con otros, los otros son responsables ante ella, deben acogerla, no pueden manipularla como si fuera un instrumento. Es en sí misma un fin y demanda de todos acogida y protección.

El deber humano más elemental es ayudar al hermano a vivir la última llamada que recibe en esta tierra. Si la vocación personal tiene un sentido central en nuestras vidas, ella lo tiene máximamente en el momento en que la vida camina a apagarse. Cuando no quedan casi los rasgos de las cualidades que le han dado relieve al individuo, es donde resplandece más la pura dignidad. Donde se hace enteramente pasivo es donde resplandece el valor de la acogida como condición fundamental del trato de las personas. Donde el hombre se hace impotente para reivindicar su derecho, resplandece la fuerza de nuestra responsabilidad hacia él. Acogida y responsabilidad son dos pilares de la sociedad humana. La muerte de cada ser humano nos trae una lección de esas virtudes.

\section{Dignidad del embrión humano}

Vamos a ordenar esta exposición de acuerdo a las siguientes preguntas:

1. ¿Qué es un embrión humano? A lo que adelantamos la respuesta que propondremos: es un organismo perteneciente a la especie humana.

2. ¿Qué trato corresponde darle a ese organismo? A lo que responderemos: el que es debido a una persona humana.

3. ¿Qué se puede inferir de una sociedad que le niega ese trato? A lo que responderemos que ella no alberga un respeto cabal a la persona humana.

\section{1. ¿Qué es un embrión humano?}

Queremos intentar una respuesta muy parcial, muy limitada, pero que no recurra todavía a nociones filosóficas que hoy son compartidas sólo por algunos; que se apegue en este apartado más bien al lenguaje de las ciencias naturales. Creemos que esta manera de proceder presenta algunas ventajas en cuanto posibilidad del diálogo.

La respuesta es casi engañosamente simple: es un organismo de la especie humana. Pero para entender esta respuesta en sus implicaciones hay que clarificar los términos. ¿¿Organismo animal? ¿Cuándo decimos que estamos frente a un organismo? Pensemos en cualquier clase de organismo, desde un protozoo a un verme (gusano) o a un mamífero (gato).

Un organismo es una unidad discreta, una entidad biológica que se distingue claramente de su medio, del cual lo separa una capa más o menos complicada de estructuras que vienen a constituir el límite o borde del 
organismo. Para una ameba será la membrana celular y el glicocálix, para un mamífero el revestimiento de piel y de mucosas. Todo organismo tiene un borde, y a través de este borde el organismo intercambia materia y energía con el medio. El borde que delimita la unidad discreta circunscribe un sistema termodinámico que recibe del medio materia y energía y las entrega transformadas, o sea delimita lo que se podría llamar un sistema dinámico fisicoquímico abierto y de composición muy compleja.

Todos los organismos se caracterizan por una trayectoria de desarrollo, de complicación, de autoorganización, que sigue un curso perfectamente previsible. $\mathrm{Si}$ observo un organismo de una especie determinada en un momento dado de su vida puedo prever cuál será su estado en un instante posterior. Nos interesa destacar que este fenómeno universal en los organismos animales de autoorganización ordenada y de curso predecible deriva directamente de que sus componentes químicos tienen formas y propiedades especificadas con alta precisión: poseen un "alto grado de información" y desenvuelven sus reacciones de interacción química dentro de los límites establecidos por un borde. Todas estas propiedades son comunes a los organismos, desde el primer instante de su constitución hasta la disolución del sistema termodinámico en la muerte.

Claramente este sistema empieza con la penetración del espermatozoide en el ovocito. En ese instante se generan -en el espacio confinado por la membrana celular- las cadenas continuas de reacciones químicas coordinadas entre los componentes paterno y materno que caracterizan el desarrollo. Inmediatamente antes de ese instante hay dos células independientes, el espermatozoide y el óvulo, que no están circunscritas por un borde común y que tienen destinos o trayectorias propias, enteramente distintas de la que se hará presente en el óvulo al ser fertilizado. Inmediatamente después tenemos un organismo en evolución.

Pero también, e insistiendo un poco sobre el desarrollo del huevo fecundado, él es claramente un organismo de la especie humana. El más simple de los estudios de sus cromosomas así lo acredita, y más todavía lo acredita su trayectoria normal de desarrollo que a través de distintas etapas lo lleva a la adultez y la muerte.

Además, cada embrión es un sistema dinámico en el cual se combinan de manera única por lo menos dos tipos de componentes: los que constituyen sus genes y los que forman el resto de los componentes celulares: en el caso del zigoto, el citoplasma. Por razones que se entienden bien desde el ángulo fisicoquímico, estas peculiaridades determinan trayectorias de desarrollo diferentes, aun en el caso de los gemelos univitelinos. Por eso, el embrión es un organismo humano único en cualquier estado de su desarrollo, distinto de todos los otros de su especie que se hallen en estado comparable de evolución.

Todo esto vale entonces desde el momento de la fecundación. No hay razón sólida para pensar que un embrión es menos un organismo humano antes de la implantación en el útero que después de ella: los famosos catorce días del informe Warnock son un plazo convencional y dictado por razones más bien interesadas, pero sin base conceptual que resista el análisis. Los eventos de la fecundación son muy rápidos; a los pocos minutos de penetrar el espermatozoide se inicia un juego recíproco entre sus componentes y los del óvulo para dar inicio a un proceso enteramente nuevo: el centriolo del espermatozoide gobierna los movimientos de la primera división del huevo, los productos del citoplasma ovular ayudan a descondensar la cromatina del espermio, la síntesis de ADN y la transcripción de genes aportados por el espermatozoide pueden comenzar antes de que se fusionen los pronúcleos. Los componentes de las que fueron dos células trabajan ahora armoniosamente como partes de una sola: se ha iniciado la trayectoria (en el sentido de trayectoria en el espacio de fases de un sistema fisicoquímico) propia de un organismo.

\section{2. ¿Qué trato merece un organismo humano? ¿Desde qué momento merece el trato debido a una persona?}

Puesto de otro modo, ¿desde qué momento tiene el derecho a la vida? Pensemos por un momento en este concepto tan peculiar de "derecho a la vida". La propia existencia no es una cosa a la que uno tenga un derecho que sea de la misma especie que los demás. No tengo derecho a la vida en el mismo sentido en que tengo derecho a ser propietario o a expresarme libremente. El "derecho a la vida" es más bien el fundamento o condición de todos los derechos y bienes posibles. Ciertamente, cuando morimos de muerte natural no es violado nuestro derecho a la vida, como en cambio lo estaría si nos asesinaran. Por eso preferiríamos ahora hablar más que de mi derecho a vivir (que puede ser 
una expresión vacía de contenido) del deber que tienen todos de respetar y aun de promover mi vida. $Y$ entonces la pregunta es: ¿¿desde cuándo existe ese deber respecto del embrión? De otro modo, ¿¿desde cuándo hay que tratarlo como a una persona?

Para responder hay que cambiar el modo de aproximación. Hemos presentado un esbozo o atisbo de definición o descripción fisicoquímica de un organismo. Es obvio que no existe una definición fisicoquímica, ni siquiera técnico-científica de la persona. Muy habitual es que se recurra a una caracterización empírica basada en el desarrollo de las funciones de relación, de inteligencia, del habla, entre otras, pero ello no es tan simple. Se ha argumentado $-\mathrm{y}$ por mucho que el argumento suene horrible no se puede negar su coherencia- que las funciones de relación de un feto de término, de un recién nacido, de un infante mentalmente enfermo son muy imperfectas y no pueden compararse con las de una persona propiamente tal, que habla y se conecta con su medio, y ni siquiera con las de muchos animales, de modo que éstos podrían tener incluso mayores derechos que aquéllos.

Pero las funciones de relación humanas aparecen también gradualmente en trayectorias de desarrollo y no está claro por qué, si el organismo es un sistema en desarrollo (y lo es siempre), debería preferirse algún momento especial de madurez funcional y no, por ejemplo, el de algún fenómeno de determinación que sea irreversible. Se ha hablado entonces del instante de la aparición de las primeras neuronas, pero no queda claro qué podría tener de especial este último fenómeno para darle preferencia sobre la aparición del primer esbozo del sistema nervioso en el tubo neural, el que aparece como una diferenciación en un organismo humano ya constituido y se halla irreversiblemente comprometido en el desarrollo de un sistema nervioso humano, y cuyo origen hay que buscarlo más atrás, en el mismo comienzo de la evolución del embrión.

Uno puede decir con perfecta propiedad que desde el momento en que existe un organismo humano se hallan en alguna fase de su desarrollo las funciones de relación que le son propias. Da la impresión de que cualquier punto que se escoja para decir: "Aquí se inicia el desarrollo de las funciones de relación" es completamente arbitrario y refleja el deseo de encontrar un punto de discontinuidad más bien que la existencia de tal discontinuidad. Haciendo una brevísima incursión en un terreno de filosofía que hemos evitado hasta ahora, diríamos que la persona humana existe en un cuerpo y que es propio de ese cuerpo hallarse siempre en algún estado de desarrollo.

Entonces, reformulando la pregunta, ¿cuál es el trato debido a un organismo que tiene tantas probabilidades de ser efectivamente una persona? Cuando algo muy grave está en juego -como la vida de alguien- la menor incerteza plantea un problema moral y por eso respondemos que ante cualquier mínimo grado de incertidumbre se le debe al embrión el respeto que se le debe a una persona. Yo puedo afirmar, claro está, que el embrión es siempre un organismo humano y que no hay ninguna evidencia científica que sea suficiente para negarle la condición de persona. $Y$ eso tiene una importancia práctica decisiva para decidir sobre el trato que debo darle.

Permítannos una comparación. Si dudo sobre si una figura que se mueve en la penumbra es un ser humano o no lo es, y sin embargo disparo en su dirección, lo que estoy poniendo en evidencia es que desprecio la condición humana. Si la tuviera en alta consideración, en la incerteza yo estaría obligado a abstenerme de hacer fuego, ya que está en juego algo tan importante como su vida.

Pero el mundo biomédico de hoy muestra un creciente desarrollo de acciones destructivas contra embriones y fetos: la manipulación embrionaria, el aborto, para no hablar del infanticidio, muestran que estos organismos humanos son tratados como cosas y de ningún modo como personas.

\section{3. ¿Qué significa que se le niegue al embrión el derecho a vivir?}

En el estado actual de nuestros conocimientos, no importa tanto la seguridad de que el organismo embrionario sea una persona, como que no existe un respeto adecuado a la persona humana; no tanto las dudas sobre el "estatus" del embrión como el desdén por el hombre.

La postura tolerante frente al aborto o a la experimentación o manipulación de embriones no sería posible sin un trasfondo de menosprecio a la persona humana en general. Es paradójico que esa postura sea muy difícil de conciliar con las principales corrientes de las que se nutre la ética contemporánea. Éstas necesitan en realidad de la persona humana. Es el testimonio involuntario que aportan sistemas éticos rígidamente 
racionalistas y aun ateos. En efecto, podemos observar una ética radicalmente utilitarista como la bioética que preconiza Singer, o bien la llamada "pragmática trascendental" de K. O. Appel, o el "velo de la justicia" del que habla Rawls, para no mencionar sino unos pocos. Todos ellos tienen como punto de partida el carácter universalmente obligatorio de la ética y, por tanto, la condición única de la persona humana, capaz de formular principios de comportamiento libre que sean universalmente obligatorios. Así se responde en el fondo a la exigencia de Kant, pero ninguna de estas posturas da una respuesta satisfactoria a una cuestión que es lógicamente previa: ¿por qué habría de sujetarme a normas de racionalidad? ¿Por qué habría de considerar que mi persona es algo cualitativamente diferente del resto de la realidad? Carecería de sentido una ética racional que no concediera a la persona humana un sitio propio y previo a su formulación, pero en alguna forma ese sitio está necesitado de justificación. El verdadero problema de la ética no es determinar cuál sea la conducta más racional, sino establecer por qué habría ella de ser seguida. Es un problema de sentido.

Esta perplejidad emerge en un mundo práctico, racional, inspirado por el positivismo y las ciencias naturales, para el cual la realidad es en cierto modo homogénea y no presenta elementos dotados de una peculiar dignidad. El propio conocimiento científico de la psique humana ha erosionado la experiencia del "yo" al subsumirla en el juego de las leyes naturales y ha contribuido a desplazar el yo "fuerte" del hombre para reemplazarlo por un "yo" débil, del estilo posmoderno, que ya no dice "yo pienso" sino "se piensa".

Sin embargo, esa visión no escapa al juicio implacable formulado hace ya un siglo por Nietzsche. Esa realidad homogénea, manipulable según las leyes que la razón descubre en ella, es en realidad un mundo sometido a la voluntad de poder. No podemos vivir en un mundo en el que neguemos valor a las cosas que nos rodean. $\mathrm{Si}$ esos valores no están arraigados en el ser mismo de las cosas sino que son creaciones nuestras o evidenciadas a través nuestro sin referencia a la verdad, ellos pasan a ser simplemente la expresión de la voluntad de poder y cada hombre organiza el pedazo de mundo que le corresponde, con arreglo a ella. En un mundo así, hasta los consensos pierden toda significación trascendental de acuerdos entre seres libres y se transforman en una manera de convivencia que persigue evitar peores conflictos. Por eso tenemos una especie de necesidad moral de las personas. Se da hoy día una misteriosa nostalgia por la persona. Sentimos que sin ella no podemos vivir humanamente. Pero eso no es suficiente.

La relativización y la trivialización de la vida humana, la reducción de la persona a la categoría de objeto entre los objetos, la supresión de su carácter único e intangible es en realidad la supresión de la manifestación por excelencia de Dios a los hombres y por lo tanto una verdadera negación de Dios.

\section{Dignidad de la familia y Derechos Humanos}

La Declaración de los Derechos Humanos no respondió a ninguna postura filosófica o religiosa determinada, sino que fue provocada por los grandes horrores de la Segunda Guerra Mundial. Como el articulado de la Declaración hace prescripciones bastante precisas sobre régimen político, no sería tampoco lógico, si no se quiere caer en un raciocinio circular, buscar el fundamento de la Declaración en el propio ideal político que ella propone. Sin embargo, a pesar de esta forma de "neutralidad ideológica", ya la primera mirada al texto revela algunos supuestos del documento.

El primero de ellos es su pretensión de ser universalmente vinculante. La Declaración es presentada como "ideal común por el que todos los pueblos y naciones deben esforzarse" (proclamación). Ella aspira entonces a darle una forma jurídica a un sentido moral de la humanidad, que no se entiende si no pretende universalidad.

A continuación, el escrito apunta hacia principios que se suponen reconocidos por todos los seres humanos, hasta el punto de que no requieren de mayor justificación. Empieza con la afirmación de que "la libertad, la justicia y la paz en el mundo tienen como base el reconocimiento de la dignidad intrínseca y de los derechos iguales e inalienables de todos los miembros de la familia humana" (considerando No 1). Y afirma además (art. 1) que "todos los seres humanos nacen libres e iguales en dignidad y derechos", y luego que "toda persona humana tiene todos los derechos y libertades proclamados en esta Declaración, sin distinción alguna..."

"Dignidad" y "derechos" configuran una condición especial y única, propia de personas en las cuales se aúna la condición de sujetos con la apertura a una verdad 
que las trasciende. La Declaración supone la noción del hombre como ser responsable y sometido a exigencias morales objetivas que se pueden codificar. Aún más, supone la universalidad de una ley que ha de regir a muchos pueblos, de historias, costumbres y culturas diferentes y que por lo tanto debe haber persistido a través de evoluciones culturales divergentes. El hecho de que conserve una vigencia universal, manteniéndose válida para todos, sugiere un fuerte grado de inmutabilidad: los derechos humanos serían no sólo universales sino también permanentes. En esta forma, los derechos propuestos configuran un conjunto de bienes objetivos importantes para el hombre.

Es posible que prescripciones éticas o jurídicas de carácter universal y perdurable reflejen alguna forma de experiencia ética básica de la humanidad. Porque cuando el hombre aprueba, reprueba o regula una conducta dada, ello acontece en primer término porque la siente conforme o disconforme con lo que su propio modo de ser le impone. La aprobación es una suerte de adhesión práctica al objeto propuesto para la conducta, una verdadera connaturalidad entre el objeto propio de la acción y su agente. Se verifica un juicio de inclinación que se refiere directamente a lo concreto de la situación propuesta y que debe ser posteriormente ratificado por la razón.

El acuerdo que se exige y proclama en la Declaración no pretende fundarse en ninguna concepción particular del hombre que se halle explícitamente reconocida en ella. Sin embargo, es difícil eludir la impresión de que la aceptación de la Declaración supone un grado de acuerdo sobre lo que se ha llamado desde antiguo la "naturaleza humana". Tal vez por eso mismo ella fue aceptada como proyecto por pensadores como Jacques Maritain, sostenedores de la noción de una "naturaleza humana" de la cual fluyen derechos y obligaciones. En cambio, filósofos como Croce, afectos a una interpretación historicista de lo humano, relativizaban o cuestionaban su valor.

Creemos que este es el punto en que se articulan los problemas de la familia y bioética con la Declaración de Derechos Humanos. Desde 1948 hasta hoy se ha ido produciendo una deriva en la concepción misma del hombre, la que viene a encontrarse con la revolución en la biomedicina.

Si se analizan los contenidos de la Declaración, se observa que disposiciones como las del derecho a la libertad del artículo 3 y a las libertades sociales fundamentales (arts. 18 a 20), así como a la seguridad social (22 y al trabajo (23) se han interpretado en clave cada vez más individualista, como derechos que no tienen otro límite que el ejercicio del derecho ajeno, mientras que la definición de la familia como el elemento natural y fundamental de la sociedad, con derecho a protección por parte de la sociedad y del Estado, se ha visto debilitada por una concepción nuevamente individualista de los derechos de los niños y su contraposición a los derechos de los padres. Recuérdese que en la Declaración son los padres los que tienen derecho preferente a elegir la forma de educación que recibirán sus hijos. Si se contrasta este enunciado con el artículo 13 de la Declaración de los Derechos del Niño, veinte ańos posterior, se percibe lo que ya anotábamos, o sea, una deriva hacia la interpretación de los derechos en clave de autoafirmación individual.

Una de las derivaciones socialmente más relevantes ha sido la reivindicación de una llamada "libertad reproductiva" y de una concepción torcida de libertad de la mujer para disponer de su propio cuerpo, que conduce en su curso lógico a la plena justificación del aborto provocado. La noción de libertad reproductiva ha sido exaltada incluso por importantes juristas como Robertson, quien la considera un derecho preeminente de la mujer. La lectura en clave individualista de la realidad social se percibe aun en pronunciamientos que buscan defender el orden natural en casos puntuales. Recordemos el argumento del presidente Clinton frente al anuncio de la de una oveja: "muchos de nosotros se sentirían muy perturbados al pensar que podrían ser clonados".

Pero, junto a una antropología creciente y desbordadamente individualista, ha sobrevenido un desarrollo espectacular de tecnologías médicas y biológicas que tocan directamente a la vida personal y social de multitudes de seres humanos. Este impacto, que en último término justifica traer estos temas en conjunto con una Declaración Universal de Derechos, se debe a que las intervenciones biomédicas tienden a multiplicar sus efectos y acarrean consecuencias múltiples y de rápida difusión.

Pensemos en su impacto sobre la familia. La introducción de los contraceptivos hormonales no sólo ha determinado graves crisis demográficas sino que, además, ha desencadenado la revolución sexual al 
independizar en máxima medida el impulso genético de las responsabilidades de la procreación. Por otro lado, la familia afronta radicales cambios de concepto emanados de la fertilización "in vitro". Esta ha introducido la posibilidad de reemplazo de la procreación por la fabricación de seres humanos. Silver sostiene que la fertilización "in vitro" inaugura una nueva rama de la tecnología, la "reprogenética”, que permitirá regular todo lo concerniente a la procreación por medio de una combinación de técnicas de fertilización y de intervención sobre el genoma. Los avances registrados este año en la clonación por transferencia nuclear en mamíferos permitirán aplicar pronto esta técnica al ser humano como sistema de intervención sobre las células germinales.

La sustitución de "procreación" por "fabricación", la puesta en cuestión de todos los lazos de parentesco, consanguinidad y filiación por el reemplazo de gametos, y en forma más radical aún por la clonación, la intervención genética y la selección de embriones, son acciones que llevan a la validación social práctica y, eventualmente, a la aceptación legal de formas de cohabitación y de procreación que niegan los supuestos de la familia humana. Piénsese, por ejemplo que, aunque no tuvieran otro efecto los anuncios sobre clonación, han puesto en evidencia que la milenaria superposición entre relación genética, lazos sociales y lazos afectivos debe ser revisada para los millares de individuos que cada año son fabricados con gametos distintos de los de sus padres "sociales". Por cierto que este complejo formado por las leyes de la descendencia, los afectos y la sociabilidad humana -cuya unidad es la familia- es puesto en duro trance para mantenerse. La familia-que según la Declaración es "el elemento natural y fundamental de la sociedad" - necesita de redefinición, con lo cual se le está negando su condición de "elemento natural y fundamental”. En efecto, ¿cómo podría redefinirse algo con esas características? Ello significa que habría que reformular la Declaración, y se percibe que en los países que tienen verdadera influencia en las cosas internacionales esta redefinición no podría hacerse sin un sesgo enteramente individualista.

Pero además, cuando hay campañas de contracepción que recurren hasta a las mutilaciones, cuando los embriones sobrantes de fecundación in vitro son utilizados como objetos experimentales en investigaciones orientadas a lo que se llama el "bien de la humanidad", no hay duda de que la "dignidad" del ser humano está siendo sacrificada como objeto de la técnica, y sabemos que los objetos no son sujetos de derechos como las personas.

Existe una tendencia invasora de la técnica a tomarlo todo como objeto posible y a actuar como si todo lo posible fuera lícito. Y aquí se produce esa peculiar contradicción de nuestro tiempo por la que el ser humano, autoafirmándose por el ejercicio de las armas poderosas de la técnica, se entrega a sí mismo como objeto. En la práctica esto significa que la pregunta eludida en la Declaración: ¿qué es el hombre y de dónde emanan sus derechos? es sustituida por una más limitada y práctica: ¿quién es hombre y quién puede invocar esos derechos?

Para el pensamiento establecido en muchas partes del mundo no basta con ser un organismo individual de la especie "Homo sapiens". Muchos son sacrificados cada año en forma de abortos o de experimentación embrionaria. Ellos están excluidos de la "familia humana" de la que habla la Declaración y hay bioéticos connotados que excluyen también a los recién nacidos enfermos del "cuidado y asistencia especiales" que se deben a la infancia (art. $25 \mathrm{~N} \mathrm{22).} \mathrm{Al} \mathrm{mismo} \mathrm{tiempo,} \mathrm{las} \mathrm{prácticas}$ eugenésicas, en otro tiempo escándalo de la humanidad, se van introduciendo subrepticiamente en nuestra escena médica. Como en el chiste de Orwell: "aquí somos todos iguales, pero hay algunos más iguales que otros."

Cuando se formuló la Declaración, en 1948, estaban frescos en la memoria crímenes atroces como el de Auschwitz, y existía conciencia clara del horror del Gulag, por ejemplo. Sin embargo, nadie se habría ocupado de hacer una Declaración como esta si no hubiera existido una convicción profunda de que, en medio de tantos horrores, el ser humano se sentía efectivamente llamado a actuar bien y de que era posible iluminar su camino y fortalecer su voluntad. Centenares de millones de hombres eran pacíficos $y$, aun en medio de terribles dolores, guardaban la esperanza y el respeto por lo humano.

El intento del secularismo contemporáneo de eliminar a Dios de la vida pública ha conducido a borrar también de ella al hombre concreto y reemplazarlo por una abstracción jurídica que se disuelve ante el análisis y la crítica. Es dudoso que el ser humano pueda darse un código que efectivamente proteja su vida y sus derechos si echa al olvido lo más fundamental de esa vida: que ella es un don, no un bien cualquiera disponible, y que 
el hombre no es amo del universo sino ser contingente y creatura.

\section{La dignidad desde la filosofía y la fe}

El ser humano ha hecho un gigantesco esfuerzo intelectual a través de su historia para encontrar una definición de sí mismo capaz de dar sentido, dirección y significado a su dolor, sufrimiento y muerte. Esta ha sido una constante histórica en toda religión y en todo credo.

Muchas han sido las definiciones filosóficas del ser humano: animal racional, político, social, de trabajo, lingüista, estructural, proletario, técnico y algunas más. Lo cierto es que ni una sola ni todas juntas dan todavía razón del ser humano, todas dejan fuera un inmenso campo de valores sin definir.

Esas definiciones son "aspectuales", esto es, recurren a sólo un aspecto del ser humano. No es que el ser humano no quiera entrar en alguna de estas definiciones, es que para entrar en alguna tendría que renunciar a su estatus trascendental, tendría que dejar de ser persona.

El ser humano es más que todas estas definiciones. Más que su biología, más que su psicología, más que sus facultades y, por tanto, más que su razón y que su voluntad: su definición trascendental es el punto de apoyo de su dignidad. Este estatus no puede dárselo el ser humano a sí mismo. La "inhabitación" de este Alguien en el espíritu humano hace al ser humano abierto al Absoluto por el mismo Absoluto y, por consecuencia, abierto a los demás. Es esta presencia del Sujeto Absoluto en el espíritu de todo ser humano lo que constituye la conciencia, el poder del ser humano, la razón de ser de toda su dignidad.

Algo hay en la persona que no se reduce a la manipulación por leyes físicas y químicas: este "algo" es lo que hace a la persona "más que materia." El ser humano es incomparablemente muchísimo más que el contenido de la información genética de sus 30.000 genes, estimados por el proyecto del genoma. No existe el ser persona clausurada en sí misma.

Esta es la razón por la cual ninguna definición aspectual del ser humano puede ser punto de apoyo para la dignidad humana, porque todos estos estratos, parte constitutiva del ser humano, son distintos e incluso antitéticos entre unos seres humanos y otros.
El estado de conciencia del ser humano, nos dice el filósofo F. Rielo, no acaece con el tiempo, ni con el desarrollo o madurez biológicos, ni con el cúmulo de experiencias; antes bien, la persona humana es un ser consciente, intelectivo, volitivo y libre desde el primer momento de su concepción. Otra cosa es el ejercicio experiencial de la conciencia y de la libertad, con sus dos funciones de la inteligencia y la voluntad en su complejidad sicosomática, sometidas al desarrollo y madurez en el tiempo biológico. El ser humano posee, no obstante, vivencia primordial de su conciencia y de todo lo que le constituye como persona desde el momento de su concepción, y esta vivencia trascendente está presente en toda experiencia vivencial y experiencial en el desarrollo integral durante su vida en este mundo(2).

El "yo inhabitado por el Sujeto Absoluto", nos sigue diciendo F. Rielo, contiene en sí estos factores determinantes de unidad mucho antes de las primeras experiencias fácticas que acuden a nuestro recuerdo, pues nuestro "yo genetizado" es antes que nuestra efectiva capacidad del recuerdo, de nuestra memoria, de nuestra imaginación, de nuestros sentimientos, de nuestros afectos y, cómo no, de nuestra cultura, de nuestra educación, de nuestras formas de pensar y de actuar, de nuestros conocimientos científicos(2).

Las funciones sicosomáticas, sus contenidos de experiencias acumuladas, su objetivación en la historia y en la cultura están sometidas al proceso del conocimiento, cuya experiencia se obtiene a la par del desarrollo y madurez de sus funciones biológicas, sicológicas y sociales, en las que a su vez intervienen las circunstancias educacionales y ambientales.

El "yo" no surge con la experiencia ni con el razonamiento ni con el lenguaje ni con la cultura; al contrario, es esto lo que en el proceso viador surge de un yo sicosomatizado que, genetizado por la presencia del Sujeto Absoluto, está capacitado para ello, dentro de un límite formal abierto al límite trascendental.

El valor de la vida humana no deriva de aquello que un sujeto hace o realiza, sino simplemente de su existencia con su ser constituido en relación con el Sujeto Absoluto. En consecuencia, sea joven o adulto, sano o enfermo, embrión o neonato, genio o idiota, el valor de todo ser humano es totalmente independiente de la cualidad de sus prestaciones y de su vida. Lo que verdaderamente cuenta es su ser en relación con el Sujeto Absoluto(3-5). 
Mientras que toda relación con el otro es reveladora de mi ser persona, la relación con Dios es constitutiva. Cada uno de nosotros existe como persona porque su ser está en relación con el misterio trascendente del Ser. Si bien es verdad que cada uno se humaniza en el momento en que es acogido en una red de relaciones interhumanas, es también verdad que la acogida por parte del otro no constituye a la persona en su ser ni en su valor. El otro no me atribuye ser y valor, sino que lo reconoce, porque mi ser y mi valor están constituidos por mi relación con la alteridad fundante, con el Sujeto Absoluto(3).

Más allá de cualquier cualidad o defecto, los seres humanos tienen, sin excepción, la misma dignidad. Esta dignidad les viene no de aquellos aspectos biológicos, psicológicos o sociales que precisamente diferencian unos seres humanos de otros, sino de aquello que les es común y constitutivo, su filiación con el Sujeto Absoluto.

\section{Referencias}

1. Rodríguez Guerro A, Chuaqui B. Notas sobre la evolución del concepto de dignidad Ars Medica 2002; 4(6).

2. Rielo F. Mis meditaciones desde el modelo genético. Madrid: Fernando Rielo; 2001.

3. Faggioni M. La qualità della vita e la salute alla luce dell'antropologia cristiana. En: Qualità della vita ed etica della salute. Roma: Librería Editrice Vaticana; 2006: 28.

4. De Angelis B. La divinizzazione dell'uomo in Massimo il Confessore. Divus Thomas 2005; 42(3).

5. La dignità della persona umana e l'ambiente divino. Bologna: Ed. Studio Domenicano; 2005: 65-80.

Recibido: 9 de febrero de 2009

Aceptado: 13 de marzo de 2009 